\title{
Biopolymer Sponge for High Grade Renal Trauma: An Experimental Study in Rabbits
}

\author{
Leandro H. M. Tavares ${ }^{1 *}$, Fábio O. Vilar², José L. Aguiar ${ }^{2}$, Alexandre R. Paz ${ }^{1}$, \\ Francisco A. D. Melo ${ }^{2}$, Gustavo R. P. Negromonte ${ }^{1}$ \\ ${ }^{1}$ Department of Surgery, Federal University of Paraiba, University Hospital Lauro Wanderley, João Pessoa, Brazil \\ ${ }^{2}$ Department of Surgery, Federal University of Pernambuco, Clinics Hospital, Recife, Brazil \\ Email: $\underline{\text { Ihmtavares@bol.com.br }}$
}

Received November 30, 2013; revised December 25, 2013; accepted January 2, 2014

Copyright (c) 2014 Leandro H. M. Tavares et al. This is an open access article distributed under the Creative Commons Attribution License, which permits unrestricted use, distribution, and reproduction in any medium, provided the original work is properly cited. In accordance of the Creative Commons Attribution License all Copyrights (C) 2014 are reserved for SCIRP and the owner of the intellectual property Leandro H. M. Tavares et al. All Copyright (C) 2014 are guarded by law and by SCIRP as a guardian.

\begin{abstract}
Introduction: Acute blunt or open renal trauma sometimes requires conservative measure which involves the use of specific materials in order to adequately restore renal parenchima. The purpose of this study is to analyze the effects of the sugar cane biopolymer sponge in an experimental model of renal trauma in rabbits. Methods: Experimental prospective study was paired with twelve New Zealand rabbits. After induction of renal trauma bilateral high-grade (grade 4-collecting system, according to AAST), the sugar cane biopolymer sponge was used for homeostasis and reconstruction of the right renal parenchyma (experimental group). The same procedure was performed in the left kidney, but using the Surgifoam ${ }^{\circledR}$ sponge (Control Group). The animals were sacrificed after four weeks. Histological analysis was performed and the results were compared after statistically being evaluated. Results: Comparing the experimental group with the control, there was more inflammatory reaction and premature adhesions in the first one. Concerning the influence on efficacy and biocompatibility of the biopolymer, no serious complications like massive bleeding, haematoma, fistula or urinary stone formation were found in both groups. Conclusion: The sugar cane biopolymer sponge demonstrated good efficacy in relation to hemostatic control and reconstruction of the renal parenchyma without major complications. Future studies may direct its routine use in urologic practice.
\end{abstract}

\section{KEYWORDS}

Acute Renal Injury; Surgical Hemostasis; Absorbable Implants; Inflammation; Biocompatible Materials

\section{Introduction}

Sugar Cane Biopolymer (SCB) consists of several exopolysaccharides, and $87.6 \%$ glucose. The polysaccharides are synthesized and secreted by Zoogloea sp. when this microorganism remains in a medium rich in molasses from cane sugar [1].

The kidney is the third most injured organ in the abdominal cavity in most cases following blunt trauma; 90\% of cases are contusions or lacerations of the renal parenchyma smaller than $1 \mathrm{~cm}$. Although penetrating trauma is responsible for only $10 \%$ of renal injuries, it is generally more serious and needs surgical exploration, which often leads to loss of the organ [2].

\footnotetext{
*Corresponding author.
}

Therefore we need new substances that help in cases of extensive renal lesions. There are few reports in the literature on biomaterials and hemostatic fibrin sealants used as an aid in the reconstruction of damaged renal parenchyma [3,4].

However, there are not yet reports on the effectiveness of biopolymer membranes in renal trauma, as well as their reactions in contact with the tissues. Based on this information, we experimentally investigate the effects of SCB in kidneys of rabbits with high grade surgical renal trauma.

\section{Methods}

The study design was experimental, prospective and lon- 
gitudinal. Twenty-four renal units of 12 rabbits adult healthy males (Oryctolagus cuniculus), New Zealand lineage, weighing 2 to $3 \mathrm{~kg}$ were used because they are the most used in literature for the objective of the present study [5-7]. The right width cortex and medulla have $4.92 \pm 0.67$ and $4.5 \pm 0.62$, respectively. The left width cortex and medulla have $4.5 \pm 0.52$ and $4 \pm 0.6$, respectively [8].

Animals were submitted to open surgery through an anterior abdominal incision (open laparotomy). The renal trauma was induced by using scalpel blade No. 15, which have $1 \mathrm{~cm} \times 1 \mathrm{~cm}$, longitudinally on the anterior surface of the kidney, with $1 \mathrm{~cm}$ deep and $1 \mathrm{~cm}$ long, with visualization of urine collecting system at the time of incision in all kidneys, which characterizes the lesions grade 4 (i.e., high-grade lesion according to the classification of the American Association for Surgery of Trauma). The right kidney was sutured with 4-0, polyglactin using, within the wound, the SCB sponge, and the left kidney Surgifoam $^{\circledR}$ sponge (SURGIFOAM ${ }^{\circledR}$ Absorbable Gelatin Sponge; Johnson \& Johnson, Somerville, Massachusetts) was used as a control group. The total procedure time and the time to hemostasis were measured. The time to hemostasis was measured using a stopwatch, controlled by an instrumentation technician, starting from the time of incision to complete end of bleeding, after affixing the suture. Time was measured in seconds. Blood loss was measured by the number of gauze $(7.5 \times 7.5 \mathrm{~cm})$ soaked through by blood, mild (only one gauze), moderate (2 to 5 gauze) and high (above 5 gauze). After 4 weeks, the animals were sacrificed with $0.2 \mathrm{ml}$ of solution of drugs composed by $1 \mathrm{ml}$ Ketamine 25\% (Dopalen ${ }^{\circledR}$; Vetbrands, Paulínea, São Paulo) and $1 \mathrm{ml}$ Xylazine 2\% (Anasedan ${ }^{\circledR}$; Vetbrands, Paulínea, São Paulo)/100g animal weight [9]. Bilateral nephrectomy was performed and kidneys were sent for histological analysis, preserved in $10 \%$ buffered formalin, and after 48 hours fixation were soaked in $70 \%$ alcohol and paraffin.

Histology was assessed by an experienced pathologist, who has been blinded for assessment of the tissues, and scored as according to the intensity of the inflammatory reaction induced the presence of fibrosis at the tissue in contact with the material. Each kidney was sectioned and two sections of each organ were subjected to histological examination. The intensity of inflammation was described from the observation of exudate cellularity, the extension of the process and the presence of cellular necrosis. The intensity of the inflammatory activity was classified as follows: void — the absence of inflammatory signals; light $(1 \times)$ —exudate with cellular infiltration in small amount, reaction involving up to one third of the studied tissue, absence of necrosis; moderate $(2 \times)$ — exudate with moderate number of cellular infiltration, involving reaction between $1 / 3$ and $2 / 3$ of fabric, presence of little necrosis; intense $(3 \times)$ —exudate cell infiltration in large quantity, reaction involving more than $2 / 3$ of the sample cell necrosis intense. Fibrosis was characterized by the presence of fibroblasts and deposition of collagen in the extracellular matrix. In order to confirm the presence of fibrosis, in addition to HE staining, Picrosirius staining, evaluated by brightfield light microscopy, was also used in all slides. The present study had full approval of the Ethics Committee on Animal Experimentation of the institution.

Statistical analysis was performed using SPSS ${ }^{\circledR} 15.0$ software for Windows ${ }^{\circledR}$, and the significance was defined as $\mathrm{p}<0.05$. Nonparametric Wilcoxon Shapiro-Wilks test-paired Student's t test and McNemar was used.

\section{Results}

The average weight of the animals was $2489 \mathrm{~g}$. The weight of the kidney varied between 5 and $10 \mathrm{~g}$. The mean operative time of the procedure was $30.33 \mathrm{~min}$ (Table 1). The mean time to hemostasis with SCB was $211.2 \mathrm{~s}$ and in control group $203.4 \mathrm{~s}, \mathrm{p}=0.195$ (Chart 1). Intraoperative blood loss did not have difference between SCB and control group, $\mathrm{p}=0.480$ (Chart 2).

During the second phase of the experiment, the macroscopic inspection did not show deformities in the healing of the renal parenchyma, as well as perirenal hematomas, abscesses, urinary stone formation, fistula or urinoma in any renal unit (Photo 1).

However, scar adherences between the kidney and adjacent organs were identified, in the right side, which corresponds to the sugar cane polymer. There was no evi-

Table 1. Descriptive measures for the group and its comparison with the Wilcoxon test.

\begin{tabular}{cccccc}
\hline Variable & Group & Mean & Median & $\begin{array}{c}\text { Standard } \\
\text { Deviation }\end{array}$ & p Value \\
\hline $\begin{array}{c}\text { Kidney } \\
\text { weight (g) }\end{array}$ & SCB & 10.00 & 10.00 & 3.02 & $\mathbf{0 . 0 5 8}$ \\
& Control & 12.50 & 10.00 & 4.52 & \\
$\begin{array}{c}\text { Hemostasis } \\
\text { time (s) }\end{array}$ & SCB & 211.17 & 209.50 & 19.92 & $\mathbf{0 . 1 9 5}$ \\
Control & 203.42 & 201.00 & 18.66 & \\
Animal weight (g) & - & 2489.25 & 2521.00 & 259.52 & - \\
Surgery time (min) & - & 30.33 & 29.00 & 8.02 & - \\
\hline
\end{tabular}

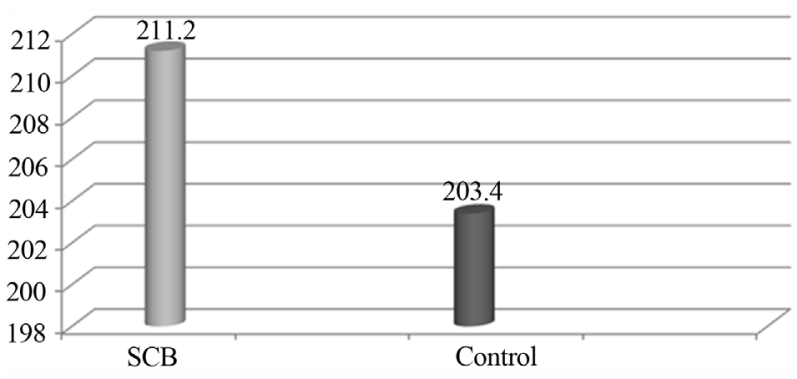

Chart 1. Mean time to hemostasis in seconds $(p=0.195)$. 


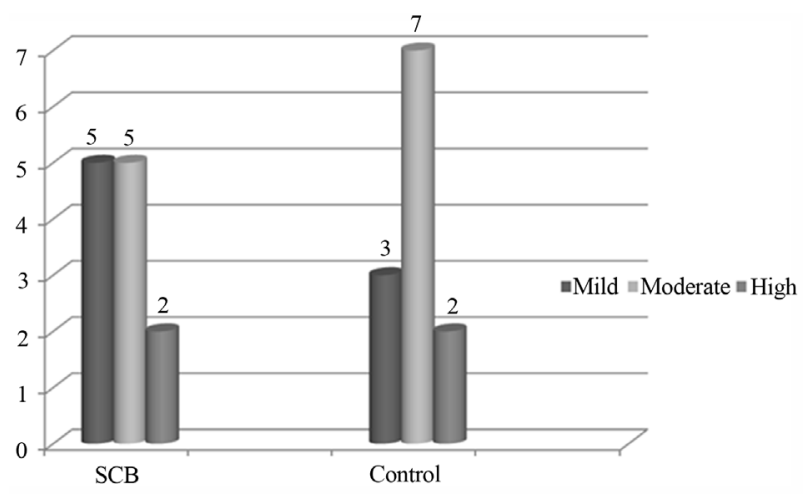

Chart 2. Intraoperative blood loss $(p=0.480)$.

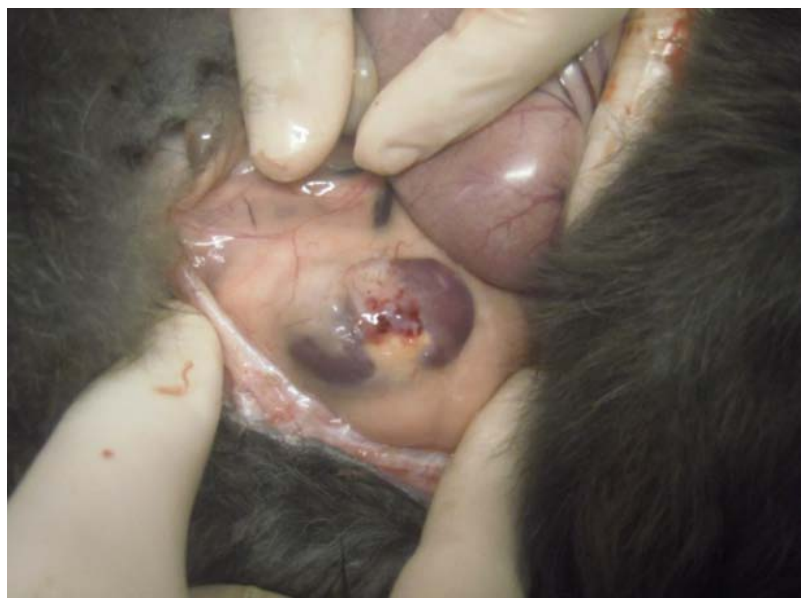

Photo 1. Good healing of SCB.

dence of change in color or texture of the biopolymer graft membrane sugar cane or Surgifoam ${ }^{\circledR}$, which were coated with a thin layer of connective tissue (Photo 2).

The degree of inflammation was classified as mild, moderate and severe. The difference between the grades of inflammatory reaction was statistically significant, $\mathrm{p}=$ 0.004 . Mild and moderate reaction was more prevalence in control group, but high reaction got greater incidence in SCB group (Table 2).

The degree of fibrosis $(\mathrm{p}=0.5)$ (Table 3$)$ and the incidence of necrosis $(\mathrm{p}=0.414)$ (Chart 3$)$ did not differ between SCB and control group. Photos were taken from SCB group to show fibrosis and necrosis in histologic analysis (Photos 3-5).

\section{Discussion}

Despite the relative frequency of blunt renal trauma penetrating lesions that needs surgical exploration represents only $10 \%$ of cases. According to the American Association of Surgery of Trauma (AAST), the renal lesions are classified as follows: grade I-bruises, abrasions and sub capsular hematomas with intact renal capsule grade II—small parenchymal lacerations extending

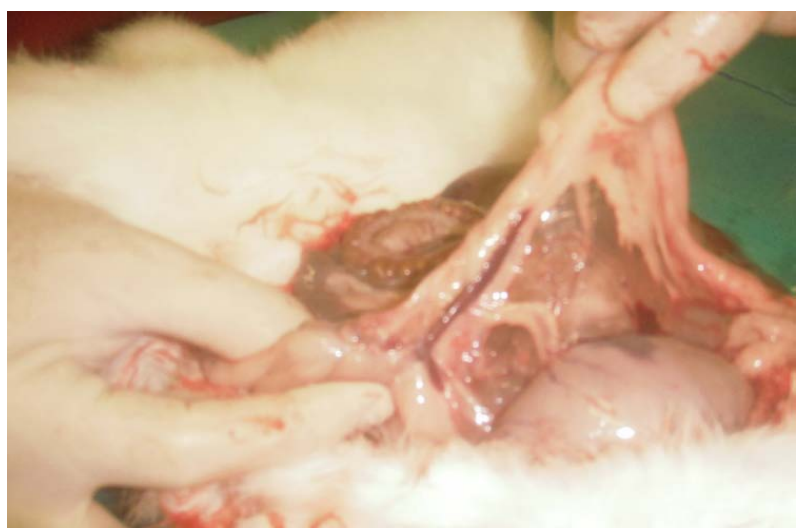

Photo 2. Presence of strong adhesions between the SCB and small bowel.

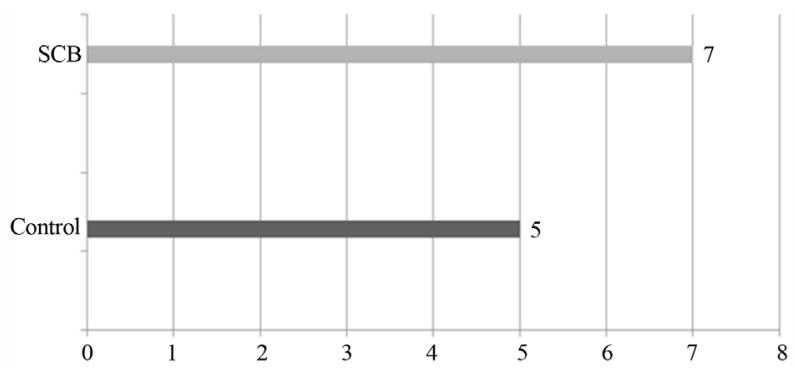

Chart 3. Incidence of necrosis in each group $(p=0.414)$.

Table 2. Inflammatory reaction by group and its comparison with the Wilcoxon test.

\begin{tabular}{cccc}
\hline Inflammatory Reaction & SCB & Control & p Value \\
\hline Mild & 1 & 6 & \\
Moderate & 0 & 5 & $\mathbf{0 . 0 0 4}$ \\
High & 11 & 1 & \\
Total & 12 & 12 & - \\
\hline
\end{tabular}

Table 3. Fibrosis by group and its comparison with the McNemar test.

\begin{tabular}{cccc}
\hline Fibrosis & SCB & Control & p Value \\
\hline No show & 2 & 0 & \\
Mild & 8 & 10 & \\
Moderate & 2 & 2 & $\mathbf{0 . 5 0 0}$ \\
High & 0 & 0 & \\
Total & 12 & 12 & - \\
\hline
\end{tabular}

to the cortical surface, not involving the medulla or collecting system, grade III-large parenchymal lacerations extending through the cortex and renal medulla, but not involving the collecting system, grade IV-large parenchymal lacerations extending to the cortex and medulla reaching the renal collecting system and any vascular 




Photo 3. Inflammatory reaction with foreign body giant cells (arrows) phagocyting exogenous material (*) (Hematoxylineosin 400x).

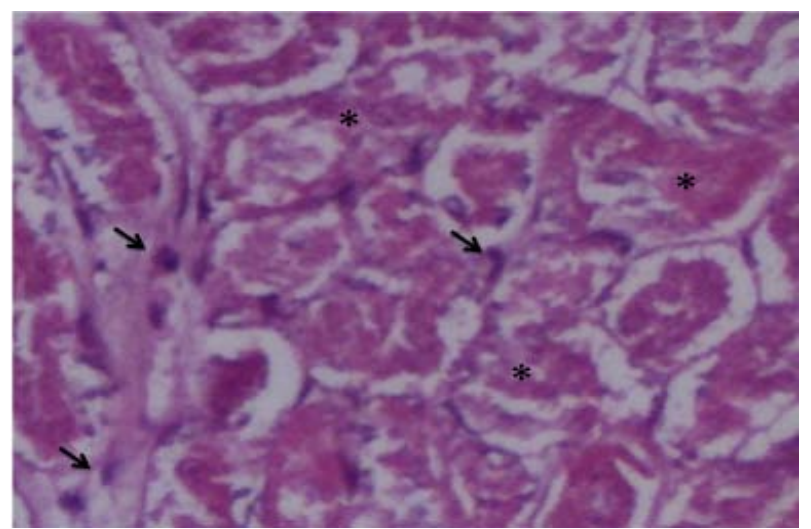

Photo 4. Necrotic tissue (*) permeated by inflammatory cells (arrows) (Hematoxylin-eosin 400 $\times$ ).

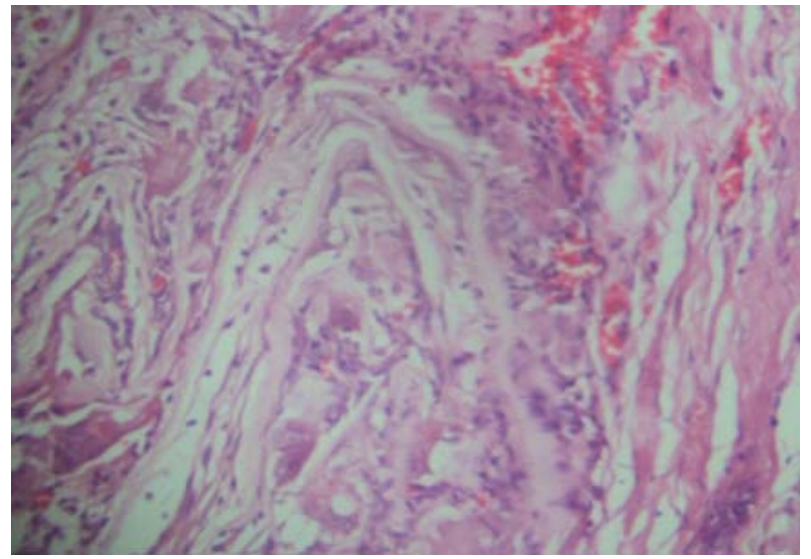

Photo 5. Reaction foreign body type mild (Hematoxylin$\operatorname{eosin} 400 \times$ ).

lesion of segmental vessels or major bleeding contained locally, and grade $\mathrm{V}$-profound and multiple lacerations of the parenchyma, extending to the cortex and medulla and the renal collecting system and vascular injury, or avulsion of the major vessels, causing extensive bleeding or thrombosis of major vessels [10].

The treatment of renal trauma is conservative in $98 \%$ of cases (almost all cases grade I, II and III, and in some cases grade IV and V). Absolute indications for surgical exploration of renal trauma are hemodynamic instability, or pulsatile perirenal hematoma expansion and persistent bleeding [10].

The way to increase the rate of renal preservation is the use of hemostatic agents such as Gelfoam ${ }^{\circledR}$, Surgicell $^{\circledR}$, or Surgifoam ${ }^{\circledR}$ Sil $^{\circledR}$, which may be necessary in more serious cases and have high efficacy, and thereby play an increasingly important role in the correction of urinary tract lesions.

Based on the experience of the nephron-sparing surgery in small renal tumors, with a gelatin matrix that was applied in an experimental model of complex renal injury in pigs it has been demonstrated that total blood loss was significantly lower than treatment with conventional sutures only [11].

The biopolymer membrane has been tested for cytotoxicity, as assessed by adhesion index, and nitric oxide production in alveolar macrophages cell viability in rats and showed no toxic response in the cells of the culture. The biopolymer sugar cane showed high biocompatibility in cytotoxicity assays [12].

The use of SCB was introduced experimentally in 2002 by researchers at the same institution who tested its effect on cutaneous wound healing with good results [3]. Then, several other studies have also been performed as a substitute in various situations, such as the tympanic membrane, bone, arteries and even tunica vaginalis [1315].

The inflammatory response to the SCB was evaluated by overlapping membranes $\mathrm{BP}$ and meshes on the parietal peritoneum of rats, by formation of adhesions with omentum and small bowel. In all rats incorporation of implanted prostheses was observed and the peritoneum was free of other abnormalities. The authors conclude that the sugar cane biopolymer can be a viable alternative, comparable to polypropylene, in dealing with renal lesions both in trauma and conservative surgery such as partial nephrectomies for renal tumors or duplicated systems.

The findings of this study corroborate the findings of previous work, where we found higher levels of fibrosis or complications such as fistulas, compared to the control group. This same observation was found in previous series that used the SCB, probably as a result of adequate biocompatibility presented by the biopolymer. However, macroscopically, there was a greater degree of adhesions to the liver and intestines, with the SCB, a fact which goes against the findings of this study [16], but that can be explained by the greater early inflammatory reaction presented by SCB, which tends to decrease with time. 
A Swedish group tested experimentally four hemostatic substances in rat kidneys: gelatin, bovine thrombin, factor VIIa and microporous polysaccharide. It is concluded that products containing gelatin obtained the fastest and best degree of hemostasis [17].

The use of hemostatic substances in the renal parenchyma has currently directed research mainly in nephronsparing surgery, greatly in surgery for small renal tumors [18].

A product that has been currently used and has shown effectiveness, safety and biocompatibility sponge is composed of fibrinogen and thrombin $\left(\right.$ Tachosil ${ }^{\circledR}$ ). Some studies in the literature have supported its use $[19,20]$.

This study demonstrated the effectiveness of the biopolymer sponge, with respect to the hemostasis of the renal parenchyma, absence of inflammatory reactions detrimental to their function, absence of urinary fistulas, or hematoma formation or stones within the collecting system, complications that could perhaps limit or contraindicate its clinical use.

The present study has limitations. The injury in this study was standardized and this did not happen in injury by firearm and blunt trauma. However, the objectives of this study were reached, because we proved the effectiveness of the biopolymer sponge. Moreover, this study was with animals, and how they present an own physiology, it is difficult to extrapolate to human being. Therefore, new studies need to be conducted.

\section{Conclusion}

Based on the findings above, it is concluded that the biopolymer sponge sugar cane has satisfactory efficacy in renal homeostasis, and offers no further damage to the remaining renal parenchyma compared to the control group, which gives a good perspective for future use in clinical urology, considering that the final cost will be much lower than the products currently used. Further work may corroborate these results and make it useful in clinical practice.

\section{Acknowledgements}

We would like to thank the surgery center's experimental UFPE for supporting our work, along with the other medical professionals involved in this experimental study.

\section{Conflict of Interest}

None declared.

\section{REFERENCES}

[1] M. Paterson-Beedle, J. F. Kennedy, et al., "A Cellulosic Exopolysaccharide Produced from Sugarcane Molasses by a Zoogloea sp.," Carbohydrate Polymers, Vol. 42, No.

\section{4, 2000, pp. 375-383.}

[2] L. W. Jonathan, B. N. Avery, et al., "Renal and Extrarenal Predictors of Nephrectomy from the National Trauma Data Bank,” Journal of Urology, Vol. 175, No. 3, 2006, pp. 970-975.

[3] J. Peters, J. Green, et al., "Kidney Salvage Using the Fibrinogen-and Thrombin-Coated Sponge TachoSil ${ }^{\circledR}$ during Nephron-Sparing Surgery for the Resection of Large Renal Tumors," Annals of The Royal College of Surgeons of England, Vol. 90, No. 5, 2008, pp. 1-3.

[4] X. M. D. Roa Saveedra, J. A. Cajigas Plata, et al., "Sellantes de Fibrin en Urología," Urológica Colombiana, Vol. 17, No. 1, 2008, pp. 55-62.

[5] K. Hwang, S. G. Kim and D. J. Kim, "Hypoglossal-Facial Nerve Anastomosis in the Rabbits Using Laser Welding," Annals of Plastic Surgery, Vol. 61, No. 4, 2008, pp. 452456.

[6] N. Y. Oct \& Gul, A. Topal, I. T. Cangul and K. Yanik, "The Effects of Topical Tripeptide Copper Complex and Helium-Neon Laser on Wound Healing in Rabbits," Expert Review of Dermatology, Vol. 19, No. 1, 2008 pp. 7-14.

[7] K. Bjorses and J. Holst, “Topical Haemostatics in Renal Trauma-An Evaluation of Four Different Substances in an Experimental Setting," Journal of Trauma, Vol. 66, No. 3, 2009, pp. 602-1

[8] R. Dimitrov, D. Kostov, et al., “Anatomotopographical and Morphological Analysis of Normal Kidneys of Rabbit (Oryctolagus cuniculus)," Trakia Journal of Sciences, Vol. 10, No. 2, 2012, pp. 79-84.

[9] F. Massole and V. Anesthesiology, "Pharmacology and technology," 4th Edition, Guanabara Koogan, Rio de Janeiro, 2003.

[10] A. J. Wein, L. R. Kavoussi, et al., “Campbell’s Urology,” 7 Edition, WB Saunders, Philadephia, 1998.

[11] E. J. Hick, A. F. Morey, et al., "Gelatin Matrix Treatment of Complex Renal Injuries in a Porcine Model," Urology Journal, Vol. 173, No. 5, 2005, pp. 1801-1804.

[12] C. M. M. B. Castro, J. L. A. Aguiar, et al., "Cytotoxicity Biopolymer Sugar Cane,” Anais da Faculdadede Medicina da Universidade Federal de Pernambuco, Vol. 49, No. 2, 2004, pp. 119-123.

[13] F. Vilar, J. L. Aguiar, et al., "Peyonie Disease: Study of a New Material with a View to Clinical Application," International Brazilian Journal of Urology, Vol. 32, No. 2, 2006, p. 167.

[14] S. V. Lima, J. L. A. Aguiar, et al., "A New Dressing for Hypospadias Surgery,” International Brazilian Journal of Urology, Vol. 32, No. 2, 2006, p. 189.

[15] E. M. Lins, "Sugar Cane Biopolymer Membrane as a Patch in Femoral Artery in Dogs,” PhD Thesis, Federal University of Pernambuco, Recife, 2007.

[16] S. Lima, A. Rangel, et al., "A New Bulking Agent to Treat Vesicoureteral Reflux: An Experimental Study,” Journal of Urology, Vol. 185, No. 1, 2011, pp. 106-108.

[17] K. Bjorses and J. Holst, “Topical Haemostatics in Renal Trauma-An Evaluation of Four Different Substances in 
an Experimental Setting,” Journal of Trauma, Vol. 66, No. 3, 2009, pp. 602-611.

[18] R. W. Hutchinson, D. Broughton, et al., "Hemostatic Effectiveness of Fibrin Pad after Partial Nephrectomy in Swine,” Journal of Surgical Research, Vol. 167, No. 2, 2011, pp. 291-298.

[19] K. H. Attar, J. Namasivavam, et al., "Kidney Salvage using the Fibrinogen and Thrombin Coated Sponge Ta-
choSil during Nephron-Sparing Surgery for the Resection of Large Renal Tumors," Annals of The Royal College of Surgeons of England, Vol. 90, No. 5, 2008, pp. 1-4.

[20] T. B. Pedersen, J. L. Honge, et al., "Comparative Study of Lung Sealants in a Porcine ex Vivo Model," The Annals of Thoracic Surgery, Vol. 94, No. 1, 2012, pp. 234240.

\section{Abbreviations}

AAST (American Association for Surgery of Trauma), SCB (Sugar Cane Biopolymer),

UFPB (Federal University of Paraíba), UFPE (Federal University of Pernambuco). 